\title{
Correction to: A Behavior-Analytic Perspective on Interprofessional Collaboration
}

Lina Slim ${ }^{1,2} \cdot$ Lilith M. Reuter-Yuill $^{3,4}$

Published online: 19 October 2021

(C) Association for Behavior Analysis International 2021

\section{Correction to: Behavior Analysis in Practice} https://doi.org/10.1007/s40617-021-00602-7

This article was updated to correct the references and in-text citations.

Publisher's Note Springer Nature remains neutral with regard to jurisdictional claims in published maps and institutional affiliations.

The online version of the original article can be found at https://doi.org/ $10.1007 / \mathrm{s} 40617-021-00602-7$

Lina Slim

linaslimtop@gmail.com

1 ASAP - A Step Ahead Program, LLC, 33 Joss Way, Millington, NJ 07946, USA

2 ABA Online Program, The Chicago School of Professional Psychology, Chicago, IL, USA

3 Department of Psychology, Western Michigan University, Kalamazoo, MI, USA

4 Comprehensive Speech and Therapy Center, Jackson, MI, USA 